\title{
Editorial
}

\section{Remote Sensing and GIS for Habitat Quality Monitoring: New Approaches and Future Research}

\author{
András Zlinszky 1,2,*, Hermann Heilmeier ${ }^{3, \dagger}$, Heiko Balzter ${ }^{4, \dagger}$, Bálint Czúcz ${ }^{5, \dagger}$ \\ and Norbert Pfeifer ${ }^{2}$
}

1 Balaton Limnological Institute, Centre for Ecological Research, Hungarian Academy of Sciences, Klebelsberg Kuno út 3, 8237 Tihany, Hungary

2 Research Groups Photogrammetry and Remote Sensing, Department of Geodesy and Geoinformation, Vienna University of Technology, Gußhausstraße 27-29, 1040 Vienna, Austria; E-Mail: norbert.pfeifer@geo.tuwien.ac.at

3 Interdisciplinary Ecological Centre, Technische Universität Bergakademie Freiberg, Leipziger Str. 29, D-09596 Freiberg, Germany; E-Mail: Hermann.Heilmeier@ioez.tu-freiberg.de

4 Centre for Landscape and Climate Research, University of Leicester, Bennett Building, University Road, Leicester LE1 7RH, UK; E-Mail: hb91@leicester.ac.uk

5 Institute of Ecology and Botany, Centre for Ecological Research, Hungarian Academy of Sciences, Alkotmány u. 2-4, 2163 Vácrátót, Hungary; E-Mail: czucz.balint@okologia.mta.hu

$\dagger$ These authors contributed equally to this work.

* Author to whom correspondence should be addressed; E-Mail: zlinszky.andras@okologia.mta.hu; Tel.: +36-87-448-244 (ext. 218); Fax: +36-87-448-006.

Academic Editor: Prasad S. Thenkabail

Received: 12 June 2015 / Accepted: 15 June 2015 / Published: 17 June 2015

\begin{abstract}
Habitat quality is the ability of the environment to provide conditions appropriate for individual and species persistence. Measuring or monitoring habitat quality requires complex integration of many properties of the ecosystem, where traditional terrestrial data collection methods have proven extremely time-demanding. Remote sensing has known potential to map various ecosystem properties, also allowing rigorous checking of accuracy and supporting standardized processing. Our Special Issue presents examples where remote sensing has been successfully used for habitat mapping, quantification of habitat quality parameters, or multi-parameter modelling of habitat quality itself. New frontiers such as bathymetric scanning, grassland vegetation classification and operational use were explored, various new ecological verification methods were introduced and integration with ongoing
\end{abstract}


habitat conservation schemes was demonstrated. These studies show that remote sensing and Geoinformation Science for habitat quality analysis have evolved from isolated experimental studies to an active field of research with a dedicated community. It is expected that these new methods will substantially contribute to biodiversity conservation worldwide.

Keywords: remote sensing; habitat quality; biodiversity; nature conservation; Natura 2000

Biodiversity is the single most threatened resource of humanity [1]. Strong commitments to protecting biodiversity have been made at global, continental and national levels, calling for an evidence-based approach to conservation. However, biodiversity is inherently difficult to quantify. Most of the operative approaches seek to quantify biodiversity of an ecosystem at a specific location either as: (1) the diversity of distinct "taxa" (species, functional groups, etc.) being present; or (2) the deviation from an ideal reference state of the studied ecosystem. Owing to its inherent normative/benchmark perspective, the second approach is particularly widely used in policy and participatory discourses. There are several working definitions which seek to operationalize the quantification of biodiversity from this perspective:

- "Habitat quality" is a concept mostly used in ecology and conservation, defined as the ability of the environment to provide conditions appropriate for individual and population persistence [2].

- "Ecosystem health" is a metric originating from the science of systems, combining system vigour, resilience and organization [3].

- Finally, "conservation status" is the concept most favoured by protected area management, defined as "the sum of the influences acting on a natural habitat and its typical species that may affect its long-term natural distribution, structure and functions as well as the long-term survival of its typical species within the territory" [4].

Further notable similar concepts include "vegetation condition" [5,6], naturalness [7], hemeroby [8] and ecological integrity [9]. What all these concepts have in common is the requirement for a complex integration of many properties of the ecosystem, producing the output as a weighted sum that takes into account their individual importance. Delivering this complex information across the wide extents of protected nature areas (e.g., the 104 million hectares protected by Natura 2000 in the European Union) requires highly efficient, standardized and reliable data collection. Traditional terrestrial methods of habitat monitoring have often proven very time-demanding [10], and their precision is difficult to evaluate due to inter-subjective differences. Additionally, many valuable habitats are difficult to access.

These problems create the need for methods to generate repeatable results over very large scales quickly and with quantified accuracy. During the last decades, progress in remote sensing technology is increasingly contributing to the identification and quantification of species, structures and objects relevant for habitat quality monitoring [10].

This Special Issue contains a collection of papers on this topic, many of which had a pre-cursor presentation at the workshop "Remote Sensing and GIS for Monitoring Habitat Quality", held on 24-25 September 2014 in Vienna, Austria [11]. The contributions address the challenge of monitoring habitat quality at various levels of information processing: The first level is identifying the location of habitats of 
interest, which is widely studied [12,13]. The second level is mapping of environmental, ecophysiological or biometric variables of a habitat that are of interest for determining habitat quality. This is established in natural resource management [14], but is rarely investigated in a conservation context as it requires the most important determinant of habitat quality to be known in advance $[15,16]$. The third, final level involves creating a model based on ecological knowledge that represents how several variables influence habitat quality, and using remote sensing to measure these variables and GIS to integrate them to a final habitat quality map. So far, this has been successful for studies of habitat quality for a particular species [17,18] but less straightforward for general conservation status [19].

- At level 1, the mapping of habitat location, the operationalisation of the country-wide application of remote sensing is an important frontier. In our Special Issue, Lindgren et al. [20] provide an operational example of data integration for systematic landscape inventorying on a national scale.

Several studies in our Special Issue explore grasslands, which are rarely investigated from the remote sensing perspective. Grasslands require very high spatial resolution, but also pose problems to remote sensing since they are spectrally very similar. Using airborne hyperspectral imagery, Burai et al. successfully mapped up to 20 grassland classes [21] and Zlinszky et al. reached a spatial resolution up to $0.5 \mathrm{~m}$ using dual-season full-waveform airborne laser scanning [22,23]. Grasslands also necessitate an alternative approach to categorization: successful examples include using fuzzy set theory to determine probabilities of class membership [23], or the study of Neumann et al. where floristic composition was investigated using species ordination without using classes at all [24].

- At level 2, new sensors and new processing algorithms have allowed mapping the main driver of habitat quality at a range of spatial scales. Mandlburger et al. have coupled airborne laser bathymetry [25] with a hydrodynamic model at the micro-habitat and meso-habitat scale to predict habitat quality for nase (Chondrostoma nasus) and how this is changed by flood events. Levick et al. applied high-density airborne laser scanning to map invasion of savannah ecosystems by an alien grass species (Andropogon gayanus) [26] at sub-regional to regional scale. Monitoring grassland management at large scales is also a challenge: MODIS data time series were successfully processed by Halabuk et al. to infer meadow cutting regimes at the scale of a whole country [27].

- At level 3, the mapping of biodiversity and conservation status, verification is an important issue, typically done through the presence and absence of the species of interest. However, in our Special Issue, several alternatives for verification are presented. Hill et al. deployed a network of nest boxes equipped with scales, directly measuring the breeding success of songbirds and correlating this with forest structure quantified from airborne laser scanning [28].

Multiple indicator datasets allow an investigation of synergies and trade-offs between habitat quality from the perspective of several taxonomic and functional groups. An example of this is the correlation of satellite imagery and laser scanning-derived indices with the abundance and species richness of birds and flying and ground-dwelling insects by Lindberg et al. [29].

Integration with current terrestrial habitat quality monitoring schemes is also an important requirement that is often considered impossible to meet due to the complexity of 
habitat quality [30]. The most extensive habitat monitoring scheme in Europe (or in fact, globally) is arguably the Natura 2000 programme, where each EU member state develops its own guidelines for field-based conservation status monitoring. These guidelines require detailed surveying of many ecologically relevant variables, most of these classically considered out of reach for remote sensing [30]. Neumann et al. [24] meticulously calculated vegetation species composition of each pixel based on an analysis of hyperspectral imagery, and from this successfully inferred Natura 2000 conservation status for a site where field access is problematic due to the presence of unexploded military ordnance. Zlinszky et al. [23] successfully mapped 12 out of 13 conservation status parameters requested by the local field-based monitoring guidelines using airborne LIDAR, and integrated the resulting datasets using the weighting prescribed by the same scheme. The result was a remote sensing-derived conservation status map that meets the requirements of Natura 2000 monitoring.

Remote sensing and Geoinformation Systems (GIS) can deliver area-covering information on variables influencing habitat quality, but also allow optimization of fieldwork by detection of change and pre-selecting sites of interest. Furthermore, by standardizing the interpretation of digital remote sensing data, quantitative habitat parameters can be determined more reliably than in the field, and subjectivity can be reduced substantially. One of the most important conclusions of our Special Issue is that remote sensing and GIS for habitat quality analysis have evolved from isolated experimental studies to an active community with several wide-scale operational applications. Habitat mapping has influenced the whole field of remote sensing to the extent that now the sensor industry is aware of this market as well.

Increasing spatial and temporal resolution is a global trend in remote sensing, and combining this with the computational formalization of ecological information allows directly deriving habitat quality. Increasing data availability is also an important trend, which will be brought to a new level when Sentinel-2 and Landsat- 8 datasets become available.

The main advantage of satellite imagery is ease of access. Many satellite datasets are available free of charge for research and non-profit applications. Their multi-temporal imaging capability is rarely matched by airborne sensors due to the cost of repeated flights.

Airborne imaging spectrometry has shown its ability to map species composition with extremely high accuracy. This technology is still only available for dedicated, small-scale surveys, but wherever complemented with ground data it delivers maps of unprecedented thematic (and especially taxonomic) detail, highly relevant for habitat quality mapping.

LIDAR data has especially proved its usefulness at levels 2 and 3 through its ability to map both radiometric and geometric properties of vegetation and thus provide information on multiple habitat quality parameters. Especially metrics of vegetation structure are very important for habitat quality monitoring and cannot be assessed at large scale from the ground. With the increasing coverage of LIDAR from national-scale surveys we expect LIDAR-based habitat quality assessment to allow a major step forward in regional-scale conservation.

Of course, this ongoing development of remote sensing does not mean that field sampling would be unnecessary. On the contrary, ground truthing of multiple parameters is extremely laborious, but the results can be worth the effort. One major issue is the comparability between sensor-based and 
field-based monitoring data. In many cases the achievable accuracies are similar but the methods and results take a different perspective on the same habitat. It is expected that assessment methods will be developed to allow a more direct relation between remotely sensed data and ecologically relevant parameters, and that remote sensing, ecology and management will all evolve in a way that facilitates compatibility.

Remote sensing and GIS are used more and more widely in governance and planning at national, regional and local scale. If habitat quality maps can be integrated into decision support systems and if their accuracy is convincing, they will allow the conservation of biodiversity and ecosystem services to be taken into account by governance in a spatially explicit way. However, this is only possible if the concept and especially the quantification of habitat quality is clear.

While the operational wide-scale application of remote sensing for habitat quality monitoring could be possible in the near future, it remains open whether local, regional or global policy is ready for the 'Big Data' challenge [31,32]. In an ideal world, a detailed quantification of biodiversity using remote sensing could impact on conservation and management in the same way that climate science and policy were boosted by the availability of global satellite data. However, remote sensing is very rarely integrated into local or regional biodiversity assessments, let alone global scale initiatives such as the Intergovernmental Panel for Biodiversity and Ecosystem Services.

If new concepts and algorithms prove to be reliable for regional-scale operational use, the technology can enter national and international-scale monitoring schemes such as required in Europe by the Habitats Directive and the Water Framework Directive. The EU has made strong commitments to protecting biodiversity but has been partially unable to monitor its progress towards meeting these targets $[33,34]$. A widespread application of remote sensing in habitat quality mapping and assessment could be a decisive step towards reaching the goals of the EU 2020 Biodiversity Strategy [35] and Convention on Biological Diversity.

\section{Acknowledgments}

The concepts and conclusions of this editorial were formulated and discussed during the International Workshop on Remote Sensing and GIS for Monitoring of Habitat Quality at TU Wien in Vienna, Austria, 24-25 September 2014. We gratefully acknowledge the active participation of all conference contributors, and the financial support of the Changehabitats2 Marie Curie IAPP project (Contract No. 251234) together with the company Riegl (http://www.riegl.com).

\section{Author Contributions}

András Zlinszky wrote the main text, with contributions by all co-authors.

\section{Conflicts of Interest}

The authors declare no conflict of interest. 


\section{References}

1. Rockström, J.; Steffen, W.; Noone, K.; Persson, Å.; Chapin, F.S.; Lambin, E.F.; Lenton, T.M.; Scheffer, M.; Folke, C.; Schellnhuber, H.J. A safe operating space for humanity. Nature 2009, $461,472-475$.

2. Johnson, M.D. Measuring habitat quality: A review. The Condor 2007, 109, 489-504.

3. Rapport, D.J.; Costanza, R.; McMichael, A.J. Assessing ecosystem health. Trends Ecol. Evol. 1998, 13, 397-402.

4. European Commission Council Directive 92/43/EEC of 21 May 1992 on the conservation of natural habitats and of wild fauna and flora. Off. J. Eur. Union 1992, 206, 7-50.

5. Gibbons, P.; Briggs, S.V.; Ayers, D.A.; Doyle, S.; Seddon, J.; McElhinny, C.; Jones, N.; Sims, R.; Doody, J.S. Rapidly quantifying reference conditions in modified landscapes. Biol. Conserv. 2008, 141, 2483-2493.

6. Gibbons, P.; Zerger, A.; Jones, S.; Ryan, P. Mapping vegetation condition in the context of biodiversity conservation. Ecol. Manag. Restor. 2006, 7, S1-S2.

7. Machado, A. An index of naturalness. J. Nat. Conserv. 2004, 12, 95-110.

8. Sukopp, H.; Hejny, S. Plants and Plant Communities in Urban Environments; SPB Academic Publishing: Amsterdam, Amsterdam, The Netherlands, 1990.

9. Woodley, S.; Kay, J.; Ecological Integrity and the Management of Ecosystems; CRC Press: Ottawa, Canada, 1993.

10. Lengyel, S.; Deri, E.; Varga, Z.; Horvath, R.; Tothmeresz, B.; Henry, P.-Y.; Kobler, A.; Kutnar, L.; Babij, V.; Seliskar, A.; Christia, C.; Papastergiadou, E.; Gruber, B.; Henle, K. Habitat monitoring in Europe: A description of current practices. Biodivers. Conserv. 2008, 17, 3327-3339.

11. Pfeifer, N.; Zlinszky, A., Eds. Proceedings of the International Workshop on Remote Sensing and GIS for Monitoring of Habitat Quality; Department of Geodesy and Geoinformation, Vienna University of Technology: Vienna, Austria, 2014. (http://rsgis4hq.geo.tuwien.ac.at/proceedings/)

12. Wang, K.; Franklin, S.E.; Guo, X.L.; Cattet, M. Remote sensing of ecology, biodiversity and conservation: A review from the perspective of remote sensing specialists. Sensors 2010, 10, 9647-9667.

13. Xie, Y.; Sha, Z.; Yu, M. Remote sensing imagery in vegetation mapping: A review. J. Plant Ecol. 2008, 1, 9-23.

14. Maltamo, M.; Naesset, E.; Vauhkonen, J. Forestry Applications of Airborne Laser Scanning: Concepts and Case Studies; Springer Science \& Business Media: Dordrecht, The Netherlands, 2014; Vol. 27.

15. Spanhove, T.; Vanden Borre, J.; Delalieux, S.; Haest, B.; Paelinckx, D. Can remote sensing estimate fine-scale quality indicators of natural habitats? Ecol. Indic. 2012, 18, 403-412.

16. Simonson, W.D.; Allen, H.D.; Coomes, D.A. Remotely sensed indicators of forest conservation status: Case study from a Natura 2000 site in southern Portugal. Ecol. Indic. 2013, 24, 636-647.

17. Zohmann, M.; Pennerstorfer, J.; Nopp-Mayr, U. Modelling habitat suitability for alpine rock ptarmigan (Lagopus muta helvetica) combining object-based classification of IKONOS imagery and Habitat Suitability Index modelling. Ecol. Model. 2013, 254, 22-32. 
18. Palminteri, S.; Powell, G.V.N.; Asner, G.P.; Peres, C.A. LiDAR measurements of canopy structure predict spatial distribution of a tropical mature forest primate. Remote Sens. Environ. 2012, 127, 98-105.

19. Riedler, B.; Pernkopf, L.; Strasser, T.; Lang, S.; Smith, G. A composite indicator for assessing habitat quality of riparian forests derived from Earth observation data. Int. J. Appl. Earth Obs. Geoinf. 2014, 37, 114-123.

20. Lindgren, N.; Christensen, P.; Nilsson, B.; Åkerholm, M.; Allard, A.; Reese, H.; Olsson, H. Using optical satellite data and airborne lidar data for a Nationwide Sampling Survey. Remote Sens. 2015, 7, 4253-4267.

21. Burai, P.; Deák, B.; Valkó, O.; Tomor, T. Classification of herbaceous vegetation using airborne hyperspectral imagery. Remote Sens. 2015, 7, 2046-2066.

22. Zlinszky, A.; Schroiff, A.; Kania, A.; Deák, B.; Mücke, W.; Vári, Á.; Székely, B.; Pfeifer, N. Categorizing grassland vegetation with full-waveform airborne laser scanning: A feasibility study for detecting Natura 2000 habitat types. Remote Sens. 2014, 6, 8056-8087.

23. Zlinszky, A.; Deák, B.; Kania, A.; Schroiff, A.; Pfeifer, N. Mapping Natura 2000 habitat conservation status in a pannonic salt steppe with airborne laser scanning. Remote Sens. 2015, 7, 2991-3019.

24. Neumann, C.; Weiss, G.; Schmidtlein, S.; Itzerott, S.; Lausch, A.; Doktor, D.; Brell, M. Gradient-based assessment of habitat quality for spectral ecosystem monitoring. Remote Sens. 2015, 7, 2871-2898.

25. Mandlburger, G.; Hauer, C.; Wieser, M.; Pfeifer, N. Topo-bathymetric LiDAR for monitoring river morphodynamics and instream habitats-A case study at the Pielach River. Remote Sens. 2015, 7, 6160-6195.

26. Levick, S.R.; Setterfield, S.A.; Rossiter-Rachor, N.A.; Hutley, L.B.; McMaster, D.; Hacker, J.M. Monitoring the distribution and dynamics of an invasive grass in tropical savanna using airborne LiDAR. Remote Sens. 2015, 7, 5117-5132.

27. Halabuk, A.; Mojses, M.; Halabuk, M.; David, S. Towards detection of cutting in hay meadows by using of NDVI and EVI time series. Remote Sens. 2015, 7, 6107-6132.

28. Hill, R.A.; Hinsley, S.A. Airborne lidar for woodland habitat quality monitoring: Exploring the significance of lidar data characteristics when modelling organism-habitat relationships. Remote Sens. 2015, 7, 3446-3466.

29. Lindberg, E.; Roberge, J.-M.; Johansson, T.; Hjältén, J. Can Airborne Laser Scanning (ALS) and forest estimates derived from satellite images be used to predict abundance and species richness of birds and beetles in boreal forest? Remote Sens. 2015, 7, 4233-4252.

30. Ichter, J.; Evans, D.; Richard, D. Terrestrial Habitat Mapping in Europe: An Overview; European Environmental Agency: Luxembourg, 2014; p. 152.

31. Carpenter, J.; Snell, J. Future Trends in Geospatial Information Management: The Five to Ten Year Vision; United Nations Committee of Experts on Global Geospatial Information Management: New York, NY, USA, 2013.

32. Hampton, S.E.; Strasser, C.A.; Tewksbury, J.J.; Gram, W.K.; Budden, A.E.; Batcheller, A.L.; Duke, C.; Porter, J.H. Big data and the future of ecology. Front. Ecol. Environ. 2013, 11, 156-162. 
33. European Environmental Agency, E. Assessing Biodiversity in Europe-The 2010 Report; European Environmental Agency: Copenhagen, Denmark, 2010; p. 58.

34. European Parliament. European Parliament Resolution of 20 April 2012 on Our Life Insurance, Our Natural Capital: An EU Biodiversity Strategy to 2020; European Union: Brussels, Belgium, 2012; p. 20.

35. European Commission. The EU Biodiversity Strategy to 2020; European Union: Luxembourg, 2011; pp. 1-28.

(C) 2015 by the authors; licensee MDPI, Basel, Switzerland. This article is an open access article distributed under the terms and conditions of the Creative Commons Attribution license (http://creativecommons.org/licenses/by/4.0/). 